Journal of Environmental Science and Public Health

doi: $10.26502 /$ jesph.96120045

fortune

Volume 3, Issue 1

Review Article

\title{
Biodiesel Preparation from Allanblackia floribunda Seed oil
}

\author{
Sylvia Adipah*
}

Department of Environmental Engineering and Science, Chongqing University, Chongqing, China

*Corresponding Author: Sylvia Adipah, Department of Environmental Engineering and Science, Chongqing University, Chongqing, China, E-mail: fransil351@yahoo.com

Received: 03 December 2018; Accepted: 14 December 2018; Published: 07 January 2019

\begin{abstract}
Sustainability access to affordable energy is also an essential component for achieving the Millennium Development Goals (MDGs), which includes reduction in poverty and hunger, facilitating education and communication, enhancement in health care services and responds to threats of climate change and growing demand of energy. The aim of this paper is to present the advantages and disadvantages of vegetable oil as a diesel fuel. The study will help promote Allanblackia floribunda cultivation and its development especially in developing countries.
\end{abstract}

Keywords: Biofuel; Renewable energy; Allanblackia floribunda; Vegetable oil; Transesterification

\section{Introduction}

Energy provides essential developments in socio-economic prospect at all levels that improve the quality of life thus reducing poverty and hunger, enhancing in health care services and responds to treats of climate change. Access to affordable energy is also an essential component for achieving the Millennium Development Goals (MDGs), which includes reduction in poverty and hunger, facilitating education and communication, enhancement in health care services and responds to threats of climate change. However, petroleum reserves that are the main source of energy is fast depleting and increasing in scarcity. Biodiesel as the promising alternative energy [1] to fossil fuel will offer developing countries some prospect of self-reliant in energy supplies at both local and national levels with potential economic, social, ecological and security benefits. Allanblackia floribunda oil, which has gained prominence in medicinal and pharmaceutical, studies but scanty in biodiesel production. 


\subsection{Biodiesel feedstock}

In general, Biodiesel can be group in three forms thus vegetable oil, animal fats and waste cooking oil. Studies suggest that waste vegetable oil is the best source of oil to produce biodiesel. Vegetable oil is one of the renewable fuels. Oil from renewable resource has become attractive because of its environmental benefits. In the near future vegetable oil will substitute petro-chemicals. Triglyceride is the basic constituent of vegetable oil that is made up of 90 to $98 \%$ of triglycerides and a small fraction of mono and diglycerides. Influential factors determines the advantages and disadvantages of vegetable oil as a diesel fuel, these are portability, ready availability, renewability, higher heat content, lower sulfur content, lower aromatic content, biodegradability, higher viscosity, lower volatility, and the reactivity of unsaturated hydrocarbon chains. The sensitivity of viscosity depends on the fuel injection system that most modern diesel engines have. To improve the performance of the diesel engine there should be reduction of fuel viscosity and vegetable oil must be blended with diesel in the presence of some additives to reduce the viscosity. The effective way to overcome problems associated with vegetable oil is the conversion of vegetable oils into fatty acids methyl esters. Another method is the transesterifictaion of vegetable oil to biodiesel as a result of methyl esters having high cetane number, low viscosity and improving heating value.

\subsection{Suitability vegetable for use as biodiesel}

1.2.1 Calorific value, heat of combustion: Heating value or heat of combustion is the amount of heating energy released by the combustion of a unit value of fuels. One of the most important determinants of heating value is moisture content. Air-dried biomass typically has about 15-20\% moisture; moisture content in coals varies in the range of 2-30\%. Liquid biofuels have bulk densities compared to fossil fuels.

1.2.2 Melt point or pour point: The point where oil in the solid form starts to melt in the presence of temperature. The temperature can fall below the melting point causing the fuel tank to be reheated.

1.2.3 Cloud point: This is where oil starts to solidify in the presence of temperature. To avoid waxing of the fuel while operating the engine below temperature, heating will be needed.

1.2.4 Flash point: The application of the ignition source ignites the fuel at a minimum temperature. Proper safety and handling of the diesel fuel is due to minimum flash point temperature.

1.2.5 Iodine value: Different biodiesel fuel is measured due to the chemical stability properties. This is measured according to the number of double bonds in the mixture of fatty acid chain in the fuel by introducing iodine into 100 grams of the sample under test and measuring how many grams of that iodine are absorbed.

1.2.6 Viscosity: This measure by the amounts of oil taken for a given measure of oil to pass through a specified size depending on the thickness of the oil. Poor combustion, increased exhaust smoke and emissions is caused due to low viscosity that's insufficient lubrication for the precision of fuel injection pumps, this injection pumps can leak and increased wear. 
1.2.7 Cetane number: The relative measure of the interval between the beginning of injection and auto ignition of the fuel. Diesel engine oil will operate better above 50, lower than that may cause difficult starting, noise and exhaust smoke.

1.2.8 Density: This is the weight per unit volume. Oil that contains enough energy is denser. Diesel is denser than petrol and gives more energy as compared by their weight.

1.2.9 Ash percentage: The amounts of metals in a fuel are measured by ash. Injector tip plugging, combustion deposits and injection system wear is caused by high concentrations of metals in the fuel.

1.2.10 Sulfur percentage: The content of sulfur in the fuel is measured in percentage by weight. According to the law only small amount of percentage is allowed on road usage.

\section{Methods of Producing Biodiesel}

A number of methods are available for producing biodiesel. Crude oils can be improved by reducing the viscosities of the product to be compatible with diesel engines. The commonly used methods are blending, micro-emulsions, thermal cracking and transesterification [2].

\subsection{Blending}

Blending is reduction of concentrated solute in solution. Crude oils are mixed directly or diluted with diesel in order to improve the viscosity. A blend of 20 to $40 \%$ of vegetable oil with diesel has been tested and proven blending as promising [3].

\subsection{Micro-emulsification}

Micro-emulsion is another approach to modifying vegetable oils to fuel. Micro-emulsions are clear, stable isotropic fluids with three components (oil phase, aqueous phase and surfactant). The aqueous phase contains salts or other ingredients while the oil phase contains mixture of hydrocarbons. This ternary phase improves the spray characteristics through explosive vaporization. Micro-emulsions using butanol, hexanol and octanol have been reported to reach the maximum viscosity limit for diesel engines.

\subsection{Pyrolysis}

Pyrolysis is another method of modifying crude oil. It is the process by which one substance is converted to another by means of heat or catalyst in the absence of air or oxygen. The pyrolyzed materials have low viscosity. However, pour point, flash point and cetane number of pyrolyzed materials are greater than those of conventional diesel. The materials have equal calorific value as diesel with acceptable amount of sulfur, copper corrosion and water [1, 3-5]. Pyrolysis can be divided into three categories; conventional, fast and flash pyrolysis. 


\subsection{Transesterification}

Transesterification is the chemical process involving triglycerides and alcohol in the presence of a catalyst to form esters and glycerol as the backbone [6]. Transesterification process involves three consecutive reversible reactions. That is, triglycerides are first converted to diglycerides, and the diglycerides are then converted to monoglycerides and glycerol backbone. Catalyst is usually used to enhance the conversion. Different catalysts are used for transesterification reaction. Examples include magnesium, calcium oxides, carbonates of basic and acidic, macroreticular organic resins, alkane alumina, sulfuric acids, sulfonic acid and dehydrating agents as co-catalysts. These catalysts are generally grouped into alkalis, acids or enzymes [7].

\section{Forms of Transesterification}

Depending on the type of catalyst, transesterification is grouped into either acidic or alkaline. Acid catalyzed transesterification is also known as esterification. The choice of catalyst is normally informed by the amount of free fatty acids and water content of the oil. Usually low free fatty acids with low water content oils require alkaline transesterification while waste and non-edible oils with high free fatty acids require acid or esterification. Below are the highlights of the various transesterification processes.

\subsection{Alkali catalyzed transesterification}

Alkali catalyzed transesterification is one of the commonest processes. This is because the process proceeds faster than the other catalysts (acids and enzymes). The reaction mechanism is in three steps [7] follows: the occurence reaction of carbonyl carbon atom with anion to form a tetrahedral, the catalyst reacting with a second molecule of alcohol, the diglycerides and monoglycerides are then converted to alkyl esters and glycerol. Jha et al. [8] studied the reaction mechanism of transesterification of non-edible oil.

\subsection{Acid catalyzed transesterification}

Acid-catalyzed transesterification is not as popular as the base-catalyzed. This is due to the slow rate of reaction and the high methanol to oil ratio required. Acid-catalysts are also characterized with low activities with high temperature during transesterification. For instance acid catalysts can directly produce biodiesel from low-cost lipid feedstock with FFA greater than 6\%. Liquid acid catalysts (such as sulfuric acid) have tolerance and less sensitive to high FFA oils and can simultaneously conduct esterification and transesterification by giving relatively high yields of esters. The mechanism of acid-catalyst transesterification is shown in [9]. The process involves protonation of carbonyl group of esters, which promotes the formation of carbon cations after nucleophilic attack of alcohol that produces tetrahedral intermediate. The intermediate formed regenerate catalyst. Acid-catalysed transesterification can be carried out in the absence of water [1].

\subsection{Enzyme-catalyzed transesterification}

Enzymatic transesterification using lipase catalyst is becoming more attractive as a result of the easy product separation, less wastewater, easy glycerol recovery and absence of side reactions. Lipases are generally known to act 
on long chain fatty acids better than the short chains. Biocatalysts are more expensive and their regeneration and reusability is limited by longer operation time. The reaction yields of enzyme-catalyzed transesterification are unfavorable and thus render the enzyme process an uneconomical.

\subsection{Non-catalytic supercritical alcohol}

Non-catalytic supercritical alcohol is a new method of producing biodiesel. Under this supercritical condition, the reaction process could be completed in few minutes with relatively high yields. Studies indicate that increasing the ratio of reaction temperature to a supercritical temperature can have favorable influence on the ester conversion [10]. The main advantage of this method is the fact that purification of biodiesel is much easier as no catalyst is required during the supercritical reaction processes. Soap formation or saponification reaction is also minimal. The presence of water that has negative impact when using conventional transesterification is also no longer an issue. However, the main problem of this process is the need for high temperature and pressure, which consequently increase cost of production. Co-solvents such as $\mathrm{CO}_{2}$, hexane, propane, calcium oxide and subcritical alcohols can however, be added to reduce the operating temperature and pressure during reaction.

\section{Factors Affecting Biodiesel Production}

\subsection{Reaction temperature}

Rate of reaction is strongly affected by the reaction temperature. A high reaction temperature can decrease the viscosity of oil, which leads to an increase in reaction rate. Ideally, the reaction temperature should be less than the boiling point of the alcohol in order to ensure that the alcohol evaporates. If the reaction temperature exceeds the optimum limit, the yield of biodiesel decreases since higher reaction temperatures accelerate saponification reaction with consequent reduction in yield [11]. Depending on the alcohol and the oil, the maximum yield is mostly obtained at temperatures between 60 and $80^{\circ} \mathrm{C}$.

\subsection{Molar ratio of alcohol to oil}

Under favorable conditions, the stoichiometric ratio of transesterification reaction requires 3 mols of alcohol to 1 mol of triglyceride to yield 3 mols of fatty acid esters and $1 \mathrm{~mol}$ of glycerol allowing oil to completely convert to esters. For base-catalyzed system where the free fatty acids are usually less than $1 \%$, molar ratio of $5: 1$ or $6: 1$ is sufficient to convert the triglyceride to biodiesel [12].

\subsection{Catalyst concentration}

Catalyst concentration is a very important factor that influences the conversion of fatty acids to esters. Base catalysts are usually preferred to acid catalysts because of the high reactivity with low process temperatures. Ideally, increase in the catalyst concentration leads to increases in the conversion of triglycerides for maximum yield. However, beyond the maximum yield, the excess catalyst leads to yield's reduction as a result of soap formation. There are varieties of base catalysts with high catalytic performance. For instance Freedman et al. [13] indicated that sodium 
methoxide is one of the effective base catalysts for transesterification. Studies indicate that concentration of $\mathrm{NaOH}$ in the range of 1.0 to $1.4 \%$ (w/w) can produce 90 to $98 \%$ methyl esters [14].

\subsection{Reaction time}

The conversion of triglyceride to esters increase with reaction time. Usually the reaction begins slowly at the initial time as a result of mixing and dispersion of alcohol onto oil. The reaction however, proceeds faster with time until maximum yield is reached [13]. For base-catalysts, the yield of esters reaches maximum ideally in $2 \mathrm{~h}$ or less [14]. Acid catalysts however, require longer reaction time ( $>2 \mathrm{~h})$. Depending on the catalyst (acidic), the reaction time required for conversion of triglycerides to biodiesel could range from 4 to 24 hrs [15]. Excess reaction time can lead to reduction in the product yield [2].

\begin{tabular}{|l|l|l|l|l|l|}
\hline Alcohol type & $\begin{array}{l}\text { Molar ratio } \\
\text { of alcohol to } \\
\text { oil }\end{array}$ & Catalyst used & $\begin{array}{l}\text { Catalyst } \\
\text { amount } \\
(\%)\end{array}$ & $\begin{array}{l}\text { Optimum reaction } \\
\text { condition }\end{array}$ & $\begin{array}{l}\text { Biodiesel } \\
\text { yield (\%) }\end{array}$ \\
\hline Methanol & $5.9: 1$ & $\mathrm{H}_{2} \mathrm{SO}_{4}$ & 15 & $60^{\circ} \mathrm{C}, 24 \mathrm{~h}$ & 99.8 \\
\hline Methanol & $1: 1$ & Rhizopus oryzae & 4 & $30^{\circ} \mathrm{C}, 60 \mathrm{hrs}$ & 80 \\
\hline Ethanol & $4: 1$ & Pseudomonas cepacia & 10 & $50^{\circ} \mathrm{C}, 8 \mathrm{hrs}$ & 98 \\
\hline Methanol & $43: 1$ & - & - & $320^{\circ} \mathrm{C}, 8.4 \mathrm{MPa}, 4 \mathrm{~h}$ & 100 \\
\hline Dimethyl carbonate & $14: 1$ & - & - & $300^{\circ} \mathrm{C}, 9 \mathrm{MPa}, 15 \mathrm{~h}$ & 97 \\
\hline Methanol & $3: 1$ & - & - & $290^{\circ} \mathrm{C}, 11 \mathrm{MPa}, 15 \mathrm{~h}$ & 99 \\
\hline Methanol & $5: 1$ & $\mathrm{NaOH}$ & 1 & $60^{\circ} \mathrm{C}, 90 \mathrm{~min}$ & 98 \\
\hline Methanol & $4.2: 1$ & $\mathrm{NaOH}$ & 1.4 & $65^{\circ} \mathrm{C}, 120 \mathrm{~min}$ & 90 \\
\hline Methanol & $6: 1$ & $\mathrm{KOH}$ & 1 & $65^{\circ} \mathrm{C}, 60 \mathrm{~min}$ & 99 \\
\hline Methanol & $9: 1$ & $\mathrm{KOH}$ & 2 & $60^{\circ} \mathrm{C}, 120 \mathrm{~min}$ & 95 \\
\hline Methanol & $11: 1$ & $\mathrm{KOH}$ & 1.1 & $66^{\circ} \mathrm{C}, 120 \mathrm{~min}$ & 93 \\
\hline Methanol & $12: 1$ & $\mathrm{Alumina}$ loaded $\mathrm{KNO}_{3}$ & 6 & $70^{\circ} \mathrm{C}, 360 \mathrm{~min}$ & 84 \\
\hline
\end{tabular}

Table 1: Catalyzed transesterification of vegetable oils with optimized reaction variables $[10,16]$

\section{Biodiesel as a Transportation Fuel}

Biodiesel is an alternative burning cleaner for petroleum fuel. Biodiesel operates in the compression ignition just like petroleum diesel fuel. Biodiesel standards have been implemented to provide high biodiesel quality and user confidence. This standard can be finding in ASTM D6751 (ASTM=American Society for Testing and Materials) and the European standard EN14214. Biodiesel can be characterizing according to density, viscosity, iodine value, acid value, cloud point, pure point, gross heat of combustion and volatility. This technical characterization compares biodiesel to petroleum diesel. 


\subsection{Engine performance characteristics of biodiesel}

The presence of oxygen in the fuel is due to the heating value of biodiesel on weight basis, high specific gravity compared to mineral diesel and lower energy content per unit volume. Researchers have carried on experimental investigation to evaluate different biodiesel blends due to engine performance, for example researchers investigated preheated palm oil methyl esters (POME) in diesel engine [17] which was observed above room temperature, engine performance, brake power out put and exhaust emission. Scholl and Sorenson studied the combustion of soya bean oil methyl ester (SME) in a direct injection diesel engine. They found that most of the relevant combustion parameters for SME such as ignition delay, peak pressure, and rate of pressure rise were close to those observed for diesel combustion at the same engine load, speed, timing and nozzle diameter. They also investigated combustion and emissions characteristics with SME and diesel for different injector orifice diameter.

\subsection{Engine emissions of biodiesel}

Biodiesel is free from sulfur and it helps to reduce the problem of acid rain, thus less sulfate emissions and particulate reduction. Breathing particulate found in smoke can cause hazardous effect on health (respiratory health issues). Metals and other substances can be found in unburnt lubricating oil. Experimental studies have been carried to reduce hydrocarbon emission in the exhaust. Sufficient $\mathrm{CO}$ is converted into $\mathrm{CO}_{2}$ therefore, toxic combustion like CO from incomplete combustion of hydrocarbons.

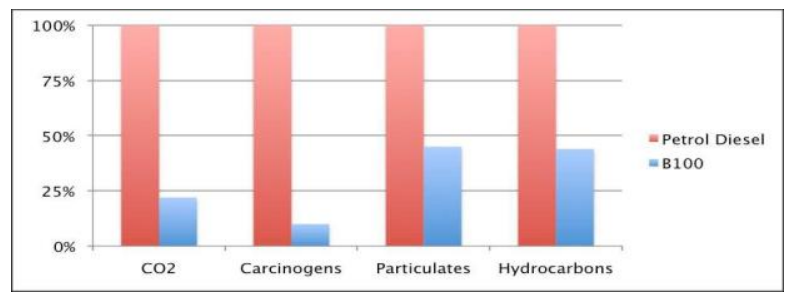

Figure 1: B100 emissions compared to petroleum diesel emissions by percentage.

(U.S. Department of Energy National Renewable Energy Laboratory, Biodiesel Handling and Use Guidelines).

\section{Conclusion}

The study is very significant and had a lot of contributions from which biodiesel is being produce from Allanblackia floribunda seed oil. This bioenergy is economical, efficient, environmentally friendly and cheap. Future research will help promote Allanblackia floribunda cultivation and its development especially in most developed and developing countries. It will also draw focus to other non-edible resources for biodiesel production. This study will contribute to enhancement and reduction of greenhouse gas emissions, regional development and social structure, especially for developing countries and enhance balance between agriculture, economic development and the environment. And finally, the biodiesel produced will help improve the lubrication properties of diesel fuel blends, which will subsequently help reduce long-term engine wear in diesel engines since biodiesel is known to be a good lubricant. 


\section{References}

1. Demirbas A. Biodiesel. A realistic Fuel Alternative for Diesel Engines (2008).

2. Leung $\mathrm{D}, \mathrm{Wu} \mathrm{X}$, Leung $\mathrm{MKH}$. A review on biodiesel production using catalyzed transesterification. Applied Energy 87 (2010): 1083-1095.

3. Agarwal M, Chauhan G, Chaurasia SP, et al. Study of catalytic behavior of $\mathrm{KOH}$ as homogeneous and heterogeneous catalyst for biodiesel production. Journal of the Taiwan Institute of Chemical Engineers 43 (2012): 89-94.

4. Singh SP, Singh D. Biodiesel production through the use of different sources and characterization of oils and their esters as the substitute of diesel: A review. Renewable and Sustainable Energy Reviews 14 (2010): 200-216.

5. Srivastava A, Prasad R. Triglycerides based diesel fuels. Renewable and Sustainable Energy Reviews 4 (2000): 111-133.

6. Huang Y, Yan Y. Lipase-catalyzed biodiesel production with Methyl Acetate as Acyl Acceptor. Z Naturforsch C 63 (2008): 297-302.

7. Demirbas A. Energy Conversion and Management (2003).

8. Jha SK, Fernando S, Filip TSD. Flame temperature analysis of biodiesel blends and components. Fuel 87 (2008): 1982-1988.

9. Meher LC, Dharmagadda VS, Naik SN. Optimization of alkali-catalyzed transesterification of Pongamia pinnata oil for production of biodiesel. Bioresource Technology 97 (2005): 1392-1397.

10. Shin HY, Ryu JH, Bae SY, et al. Biodiesel production from highly unsaturated feedstock via simultaneous transesterification and partial hydrogenation in supercritical methanol. Journal of Supercritical Fluids 82 (2013): 251-255.

11. Patil P, Gude VG, Pinappu S, et al. Transesterification Kinetics of Camelina sativa Oil on metal oxide catalysts under conventional and microwave heating conditions. Chemical Engineering Journal 168 (2011): 1296-1300.

12. Tan T, Lu J, Nie K, et al. Biodiesel production with immobilized lipase. Biotechnology Advances 28 (2010): 628-634.

13. Freedman B, Pryde EH, Mounts TL. Variables affecting the yields of fatty esters from transesterification vegetable oils. Journal of the American Oil Chemists Society 61 (1984): 1638-1643.

14. Berchmans HJ, Hirata S. Biodiesel production from crude jatropha curcas L.seed oil with high content of free fatty acids. Bioresource Technology 99 (2008): 1716-1721.

15. Shuit SH, Teong KL, Kamaruddin AH, et al. Reactive extraction of Jatropha curcas seed oil for production of biodiesel: process optimization study. Environ Sci Technol 44 (2010): 4361-4367.

16. Vyas AP. Production of biodiesel through transesterification of Jatropha oil using KNO3/AL2O3 solid catalyst. Fuel 88 (2009): 625-628.

17. Masjuki HJ, Abul Kalam M. An overview of biofuel as a renewable energy source: Development and Challenge. Procedia Engineering 56 (2013): 39-53. 
18. Altin R, Catinkaya S, Serda H, et al. The potential of using vegetable oil fuels as fuel for diesel engines. Energy Conversion and Management 42 (2001): 529-538.

19. Demirbas A. Biodiesel production via non-catalystic SCF method and biodiesel characteristics (2006).

20. Ma F, Hanna MA. Biodiesel production: A review. Bioresource Technology 70 (1999): 1-15.

21. Raja S, Gokul RS, Deepanraj A, et al. A facile Acid- cataylsed biodiesel production from the seeds of mimusops Elengi. International Journal of Applied Engineering Research 10 (2015): 2106-2109.

22. Sarin A, Singh NP, Sarin R, et al. Natural and synthetic antioxidants: Influence on the oxidative stability of biodiesel synthesized from non-edible oil. Energy 35 (2010): 4645-4648.

23. Scholl KW, Soenson SC. Combustion of soybean oil methyl ester in a direct injection diesel engine. SAE Transactions 102 (1993): 1450-1462.

24. Yalain T, Canan K, Firat A, et al. Comparison of the biodiesel quality produced from refined sunflower and waste cooking oil. Energy Exploration and Exploitation 28 (2010): 499-512.

Citation: Sylvia Adipah. Biodiesel Preparation from Allanblackia floribunda Seed oil. Journal of Environmental Science and Public Health 3 (2019): 025-033.

This article is an open access article distributed under the terms and conditions of the

Creative Commons Attribution (CC-BY) license 4.0 